\title{
HDlive in the Assessment of Fetal Facial Abnormalities
}

\author{
${ }^{1}$ Toshiyuki Hata, ${ }^{2}$ Uiko Hanaoka, ${ }^{3}$ Rina Uematsu, ${ }^{4}$ Genzo Marumo, ${ }^{5}$ Hirokazu Tanaka
}

\begin{abstract}
We present the latest HDlive images of normal fetal faces and facial abnormalities. Fetal facial anatomical structures, such as the eyes, nose, ears and mouth, are clearly evident at 12 to 13 weeks of gestation. HDlive with the use of new skin-like colors provides sonographers and physicians with a natural and anatomically realistic appearance of the fetal face. Moreover, HDlive images provide entirely new visual experiences for obstetricians owing to the anatomically realistic depiction of the normal fetal face and fetal facial abnormalities in utero. HDlive can provide clearer facial images than conventional three-dimensional (3D) sonography. In particular, HDlive is superior to conventional 3D sonography for the depiction of fetal eyes because of its shadowing effect. HDlive may be a useful diagnostic modality for the antenatal evaluation of normal fetal facial anatomy and fetal facial abnormalities.
\end{abstract}

Keywords: 3D ultrasound, HDlive, Fetal face, Normal facial anatomy, Facial abnormalities.

How to cite this article: Hata T, Hanaoka U, Uematsu R, Marumo G, Tanaka H. HDlive in the Assessment of Fetal Facial Abnormalities. Donald School J Ultrasound Obstet Gynecol 2014;8(4):344-352.

\section{Source of support: Nil}

Conflict of interest: None

\section{INTRODUCTION}

There have been numerous reports on conventional threedimensional (3D) sonographic evaluation of normal fetal facial structures and fetal facial abnormalities. ${ }^{1-7}$ However, subtle facial abnormalities are still difficult to detect using conventional 3D ultrasound. HDlive is more effective than conventional 3D ultrasound for the observation of normal and abnormal fetal facial anatomies, ${ }^{8-10}$ because HDlive uses an adjustable light source, facilitating the use of lighting and shadowing effects which increase depth perception. ${ }^{11}$ HDlive is a new surface-rendering mode,

\footnotetext{
${ }^{1}$ Professor and Chairman, ${ }^{2}$ Senior Assistant Professor

${ }^{3}$ Sonographer, ${ }^{4}$ President, ${ }^{5}$ Associate Professor

1-3,5 Department of Perinatology and Gynecology, Kagawa University Graduate School of Medicine, Japan

${ }^{4}$ Department of Obstetrics and Gynecology, Marumo Ladies Clinic, Japan

Corresponding Author: Toshiyuki Hata, Professor and Chairman, Department of Perinatology and Gynecology, Kagawa University Graduate School of Medicine, 1750-1 Ikenobe, Miki Kagawa 761-0793, Japan, Phone: +81-0878912174, e-mail: toshi28@med.kagawa-u.ac.jp
}

which uses an adjustable light source that facilitates the ability to create lighting and shadowing effects, thereby increasing depth perception. ${ }^{11}$ This technique provides such extraordinarily realistic imaging of the embryo and fetus that it is almost impossible to differentiate between actual photographs and sonographic images. ${ }^{12}$ Moreover, HDlive can provide clearer facial images than conventional 3D ultrasound. ${ }^{13}$ In particular, HDlive is superior to conventional 3D ultrasound for the depiction of eye fissures because of its shadowing effect. The present paper describes the latest state-of-the-art HDlive imaging of normal and abnormal fetal faces, and makes recommendations for future research in this field.

\section{NORMAL FETAL FACES}

The fetal facial anatomical structures, such as the eyes, nose, ears, and mouth, can be identified at 12 to 13 weeks of gestation ${ }^{14}$ (Figs 1 and 2). The nostrils can also be recognized at 13 to 15 weeks of gestation ${ }^{14}$ (Figs 2 and 3). Realistic fetal faces can be noted after 20 weeks of gestation (Figs 4 and 5). Fetal facial adipose tissue is deposited, and shows gradual accumulation after 24 weeks to term ${ }^{15}$ (Figs 6 to 9).

\section{FETAL FACIAL ABNORMALITIES}

HDlive can provide clearer facial images than conventional 3D ultrasound. In particular, HDlive is superior to conventional 3D ultrasound for the depiction of eye fissures because of its shadowing effect. ${ }^{13}$ This technique provides an extraordinarily realistic images of the fetal face, making it almost impossible to differentiate between actual photographs and HDlive images. ${ }^{12}$ HDlive offers a potential advantage over conventional 3D ultrasound. ${ }^{14}$

\section{Trisomy 13}

Fetal facial abnormalities in trisomy 13 were detected in 64.3 to $76.5 \%$ using two-dimensional (2D) ultrasound. ${ }^{16,17}$ Abnormal prenatal sonographic findings of the fetal face are cleft lip or palate, close-set eyes (hypotelorism), cyclopia, a proboscis, low-set ears, a small head (microcephaly) and small lower jaw (micrognathia). ${ }^{18,19}$ In a characteristic case of trisomy 13 at 31 weeks and 1 day, cleft lip and close-set eyes were recognized with HDlive and confirmed after birth ${ }^{13}$ (Figs 10A and B). 

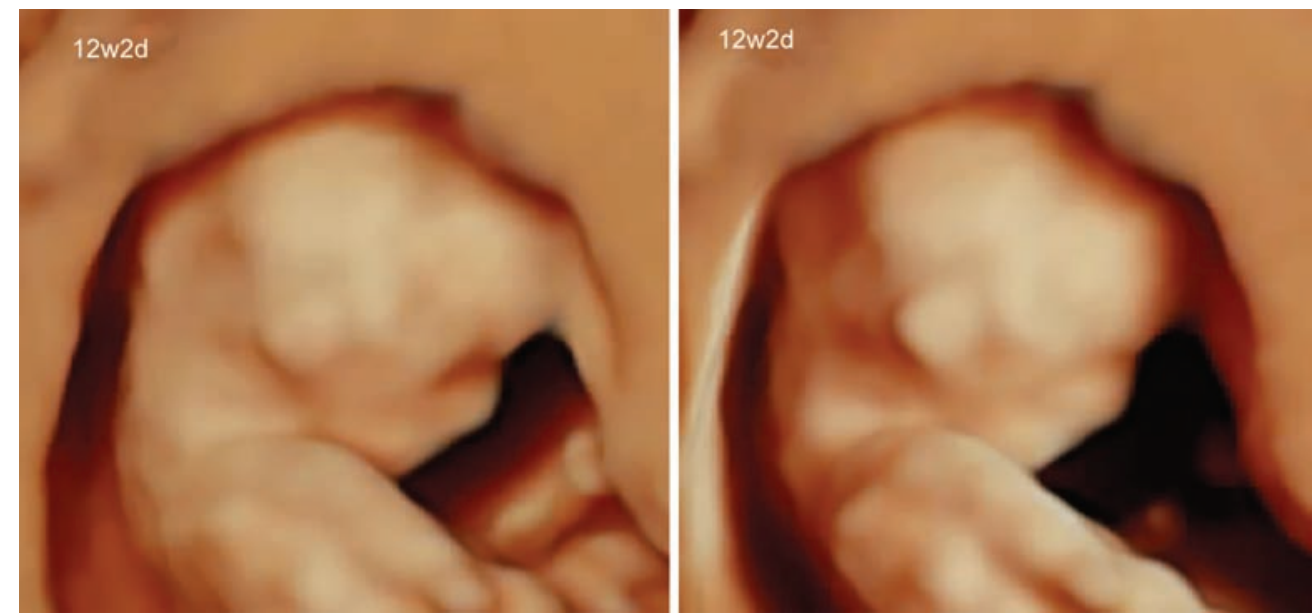

Fig. 1: HDlive images of a fetal facial profile at 12 weeks and 2 days of gestation. The eyes, nose, mouth and ears can be noted
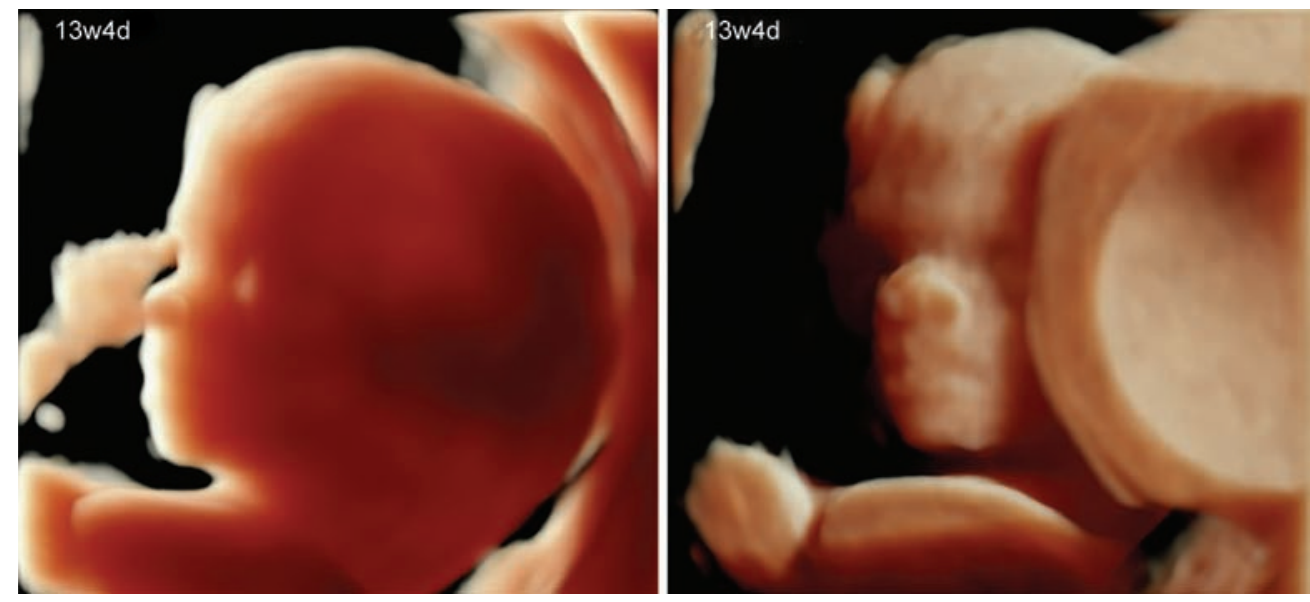

Fig. 2: HDlive images of normal fetuses at 13 weeks and 4 days of gestation. The fetal facial anatomy can be clearly identified (Courtesy: Reprinted with permission from Hata T et al) ${ }^{8}$
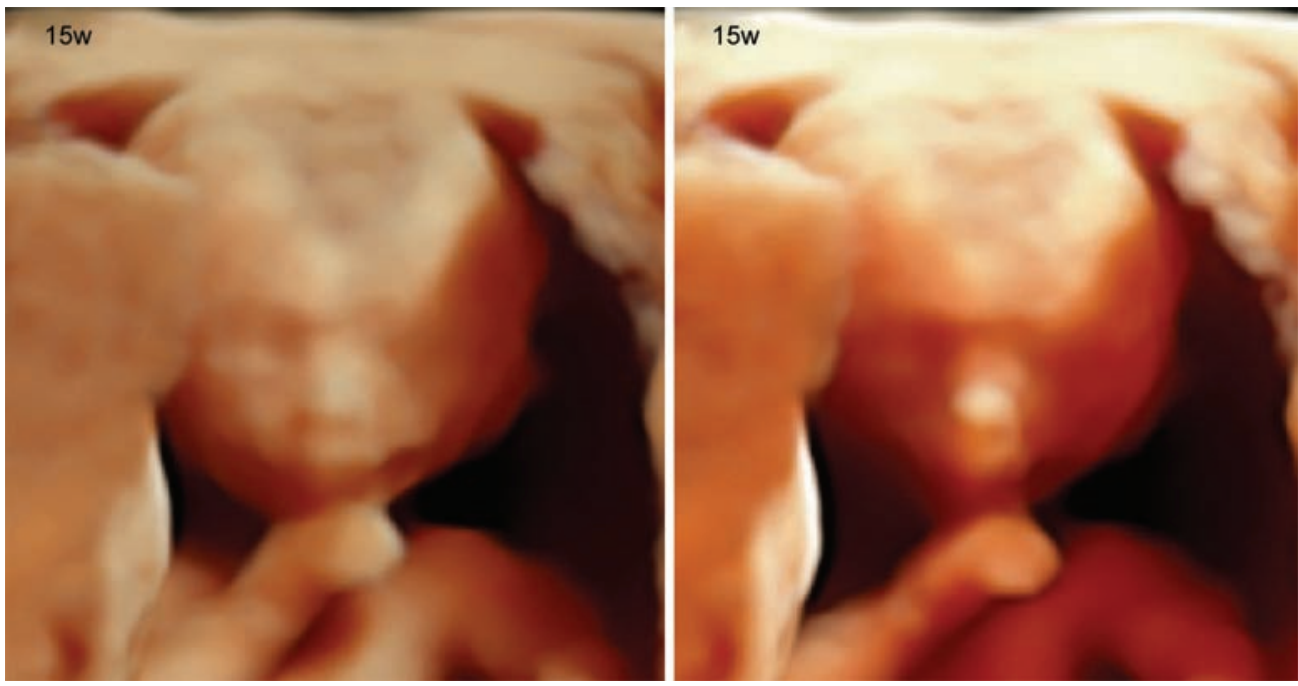

Fig. 3: HDlive images of a fetal face at 15 weeks of gestation (Courtesy: Reprinted with permission from Hata T et al) ${ }^{14}$

\section{Trisomy 18}

Fetal facial abnormalities in trisomy 18 were detected in $53 \%$ using $2 \mathrm{D}$ ultrasound. ${ }^{20}$ However, the sensitivity of antenatal ultrasound was lower for detecting facial abnormalities (26.3\%). ${ }^{21}$ Facial malformations associated with trisomy 18 include a small head (microcephaly) accompanied by a prominent back portion of the head, low-set, malformed ears, micrognathia, cleft-lip or palate, an upturned nose, narrow eyelid folds, and widely spaced eyes. ${ }^{22}$ In one case of trisomy 18 at 27 weeks 


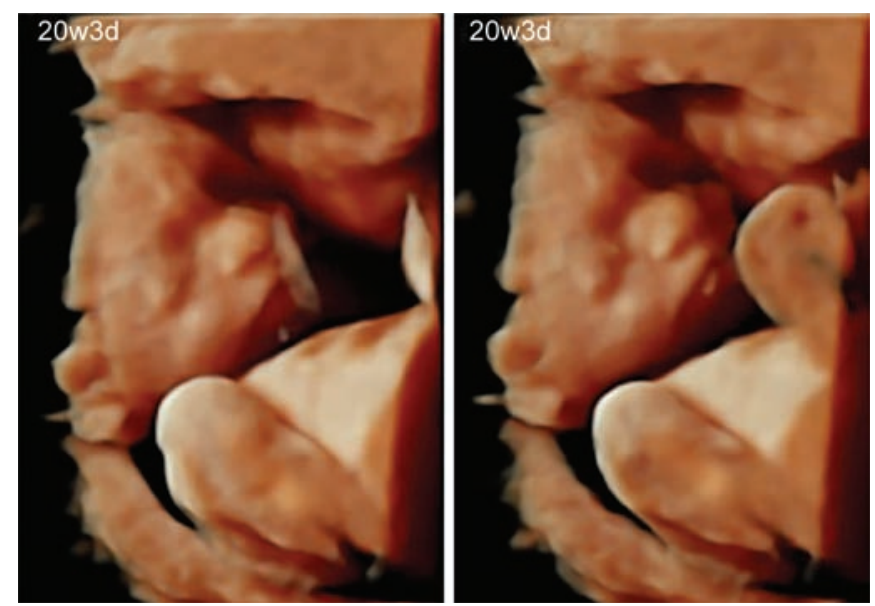

Fig. 4: HDlive images of a fetal face at 20 weeks and 3 days of gestation

and 6 days, a small head accompanied by a prominent back portion of the head, low-set ears, a small jaw, an upturned nose, narrow eyelid folds, and widely spaced eyes were identified using HDlive ${ }^{13}$ (Figs $11 \mathrm{~A}$ and B). In two other cases of trisomy 18 (Figs 12 and 13), HDlive showed more detailed features of the fetal face compared to conventional 3D ultrasound. ${ }^{8,13}$

\section{Trisomy 21}

The agreement between antenatal sonographic and autopsy findings in trisomy 21 was 100\% for hydrops fetalis, and $1.2 \%$ for facial abnormalities. ${ }^{23}$ Common facial abnormalities in trisomy 21 include a flattened nose, small ears, a small mouth, the corners of the mouth turned down and upward slanting eyes. ${ }^{24}$ In one case of trisomy 21 with hydrops fetalis at 16 weeks and 4 days, skin edema around the head and body was clearly identified employing HDlive (Figs 14A and B). In one case of trisomy 21 at 26 weeks and 1 day, a flattened nose and the corners of the mouth turned down were noted (Figs 15A and B). In one case of trisomy 21 at 29 weeks and 5 days, a flattened nose, low-set ears, the corners of the mouth turned down, and upward slanting eyes were evident by employing HDlive (Figs 16A to C). ${ }^{13}$

\section{Amniotic Band Syndrome}

Although a wide array of malformations occurs in amniotic band syndrome, severe fetal facial malformations are also included. ${ }^{8,25-27}$ HDlive provides new, realistic sensations
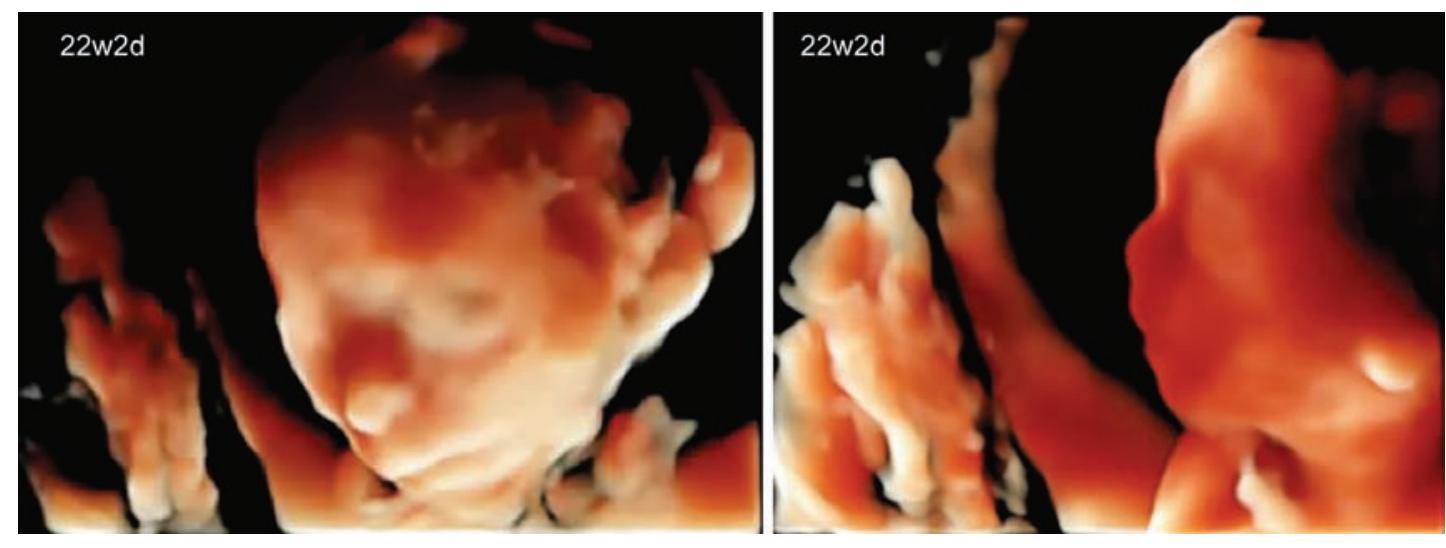

Fig. 5: HDlive images of a fetal face at 22 weeks and 2 days of gestation

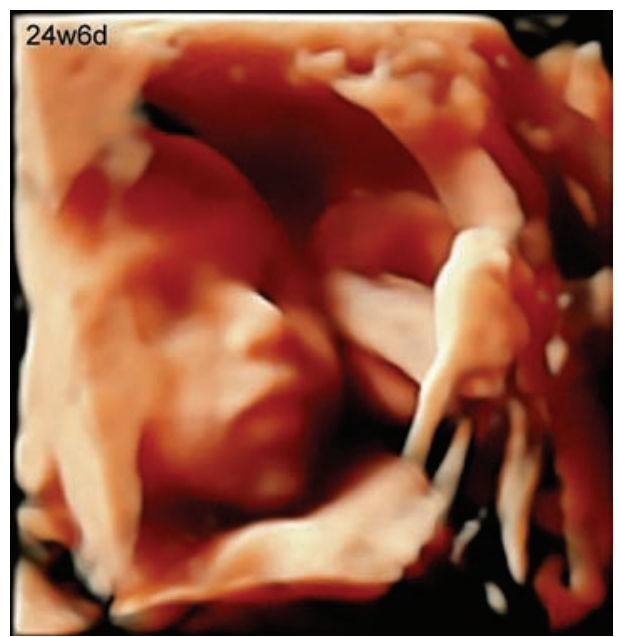

Fig. 6: HDlive image of a fetal face at 24 weeks and 6 days of gestation
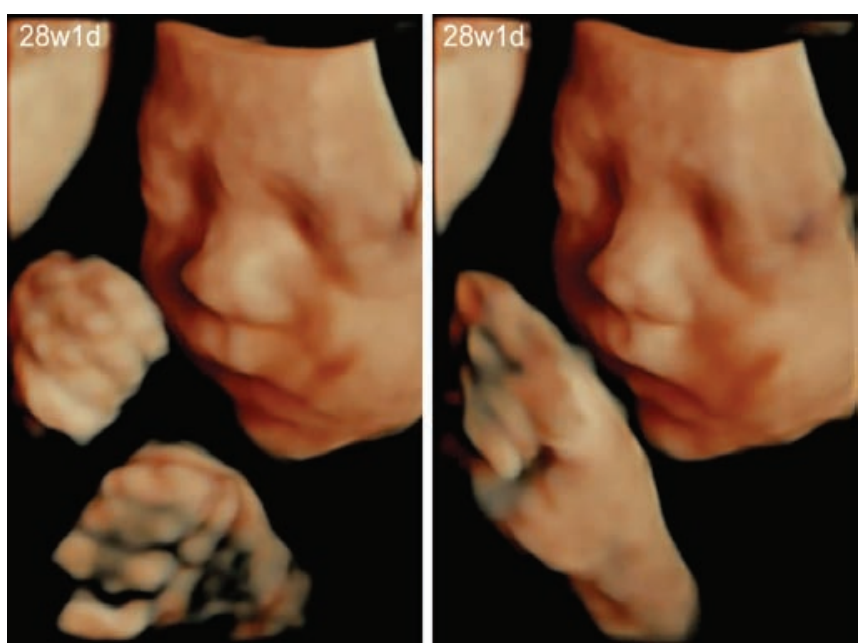

Fig. 7: HDlive images of a fetal face at 28 weeks and 1 day of gestation 


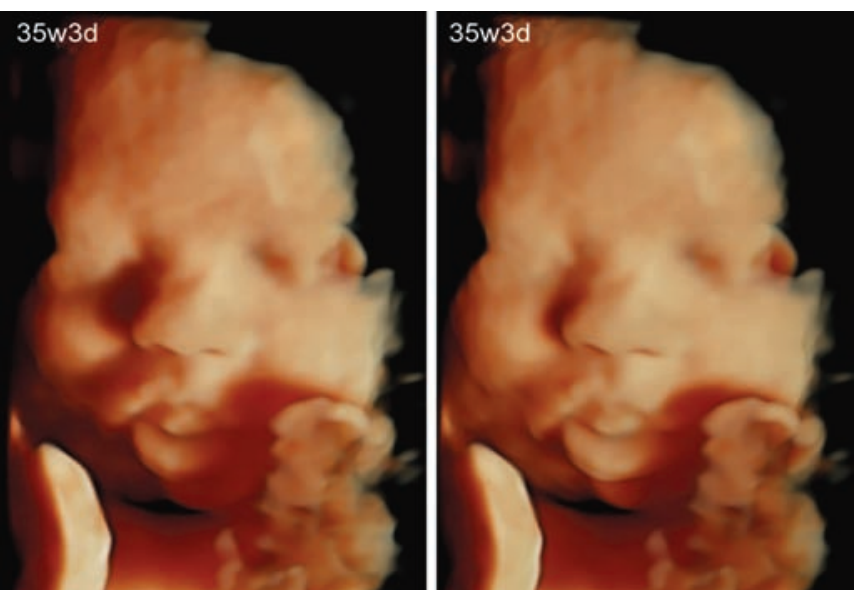

Fig. 8: HDlive images of a fetal face at 35 weeks and 3 days of gestation
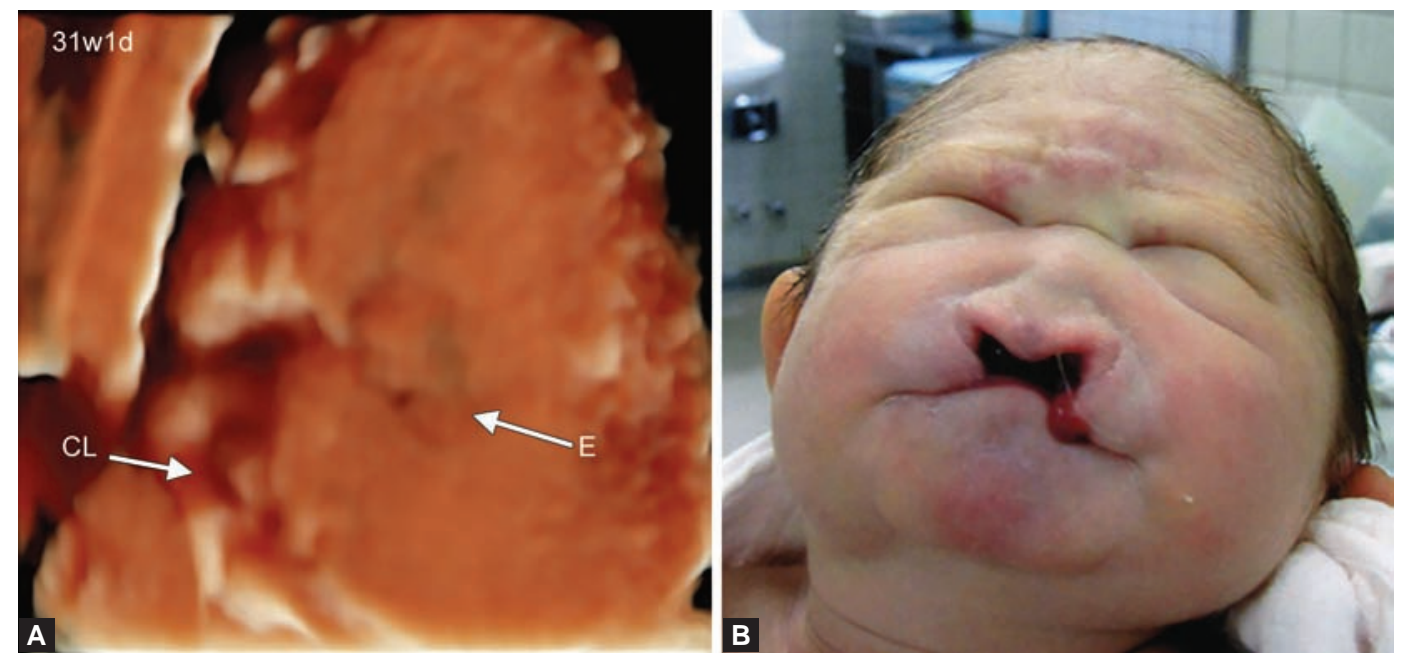

Figs 10A and B: Trisomy 13: (A) fetal face reconstructed by HDlive in a case of trisomy 13 at 31 weeks and 1 day of gestation. Close-set eyes (E) and cleft lip (CL) are noted and (B) face of a stillborn fetus
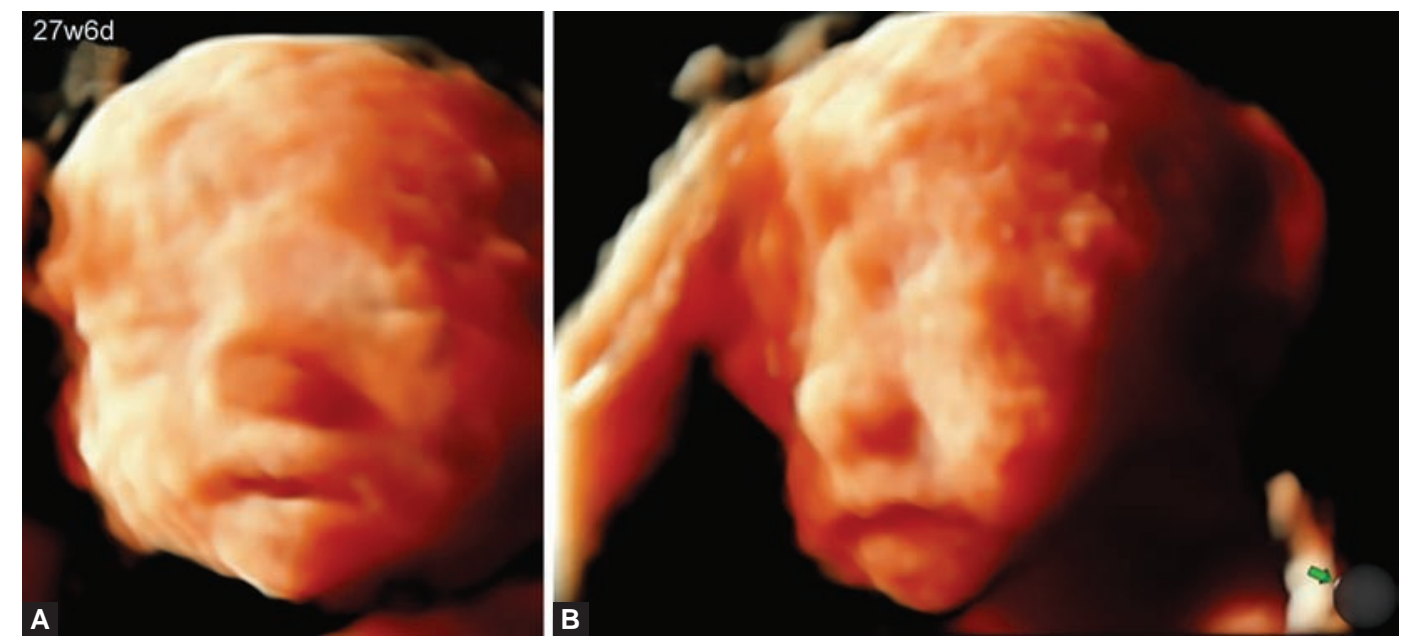

Figs 11A and B: Fetal face reconstructed by HDlive in a case of trisomy 18 at 27 weeks and 6 days of gestation. Microcephaly, hypertelorism, low-set ears, an upturned nose and micrognathia are noted using HDlive. Narrowed eyelid folds can be recognized only with HDlive: (A) frontal view and (B) left oblique view (Courtesy: Reprinted with permission from Hanaoka $U$ et al) ${ }^{13}$

for the diagnosis of facial abnormalities in amniotic band syndrome (Figs 17 to 20). In particular, the realistic depiction of amniotic bands is excellent.

\section{Cyclopia and a Proboscis}

'The cyclops is a fetus presenting a frontnasal malformation characterized by one single eye with or without 


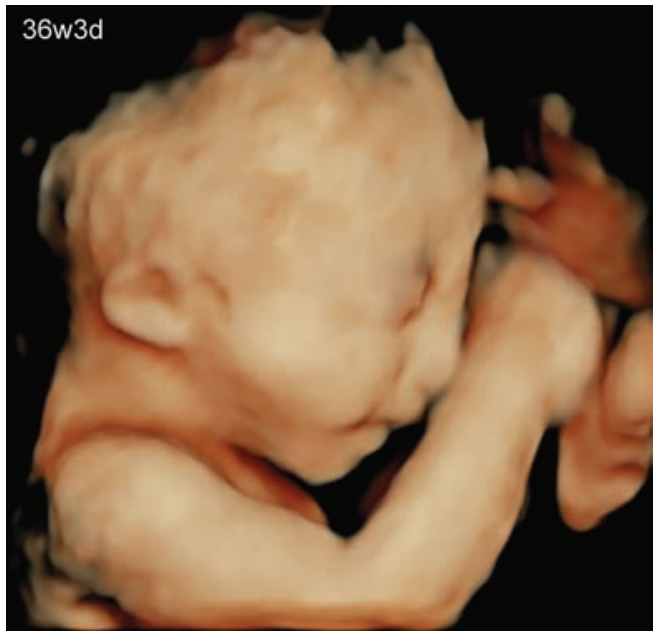

Fig. 12: Low set ears and micrognathia in a case of trisomy 18 at 36 weeks and 3 days of gestation (Courtesy: Reprinted with permission from Hata T et al) ${ }^{8}$

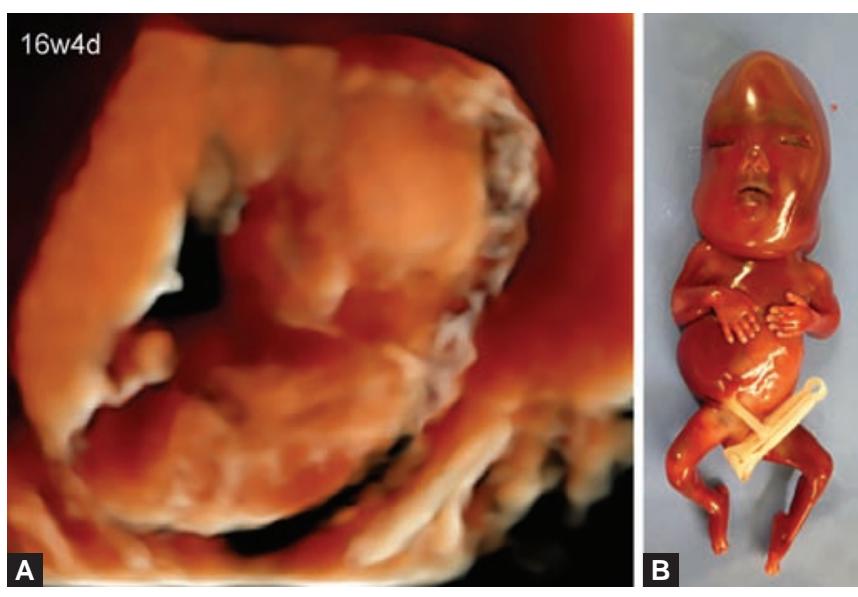

Figs 14A and B: Trisomy 21: (A) fetal face and trunk reconstructed by HDlive in a case of trisomy 21 with hydrops fetalis at 16 weeks and 4 days of gestation. Skin edema around the head and body can be clearly identified and (B) whole body of a stillborn fetus

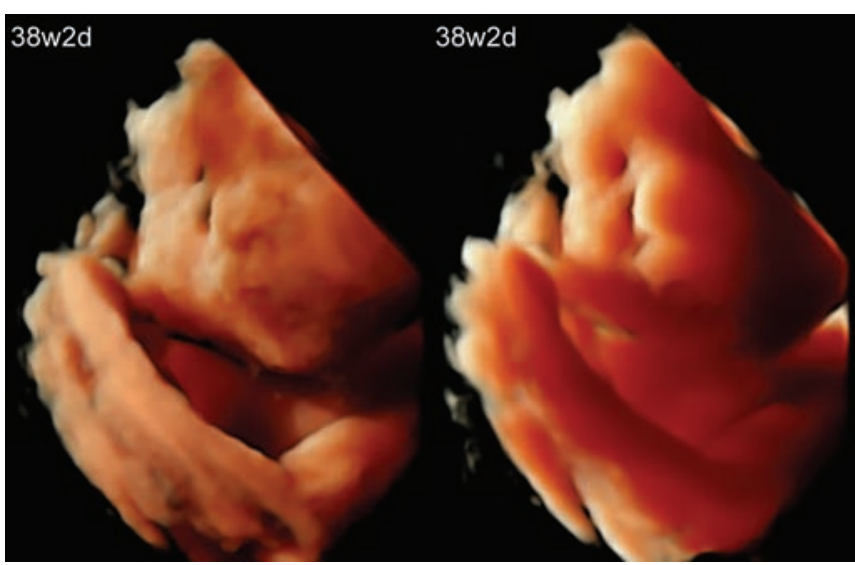

Fig. 13: Fetal face reconstructed by HDlive in a case of trisomy 18 at 38 weeks and 2 days of gestation. An upturned nose, and micrognathia are noted
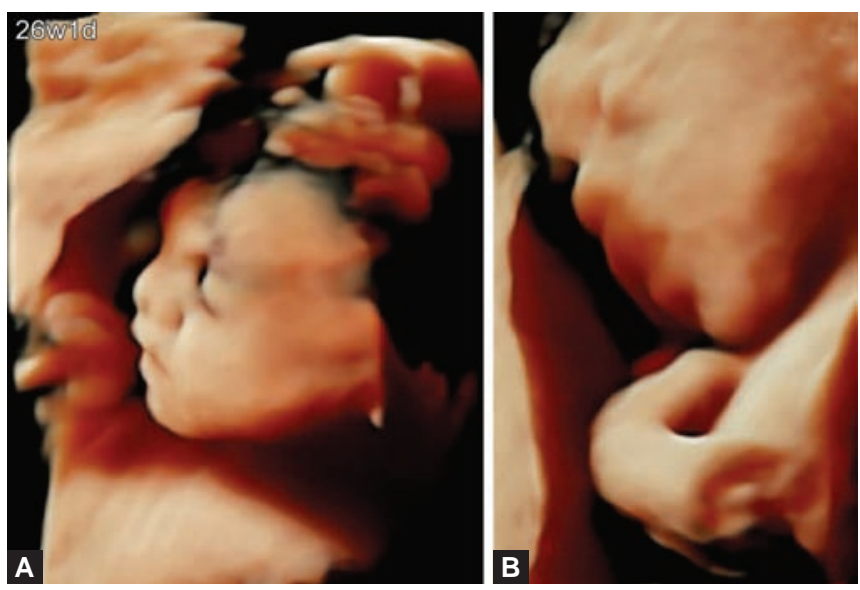

Figs 15A and B: Fetal face reconstructed by HDlive in a case of trisomy 21 at 26 weeks and 1 day of gestation. A flattened nose and the corners of the mouth turned down are noted: $(A)$ fetal profile, and (B) left oblique view
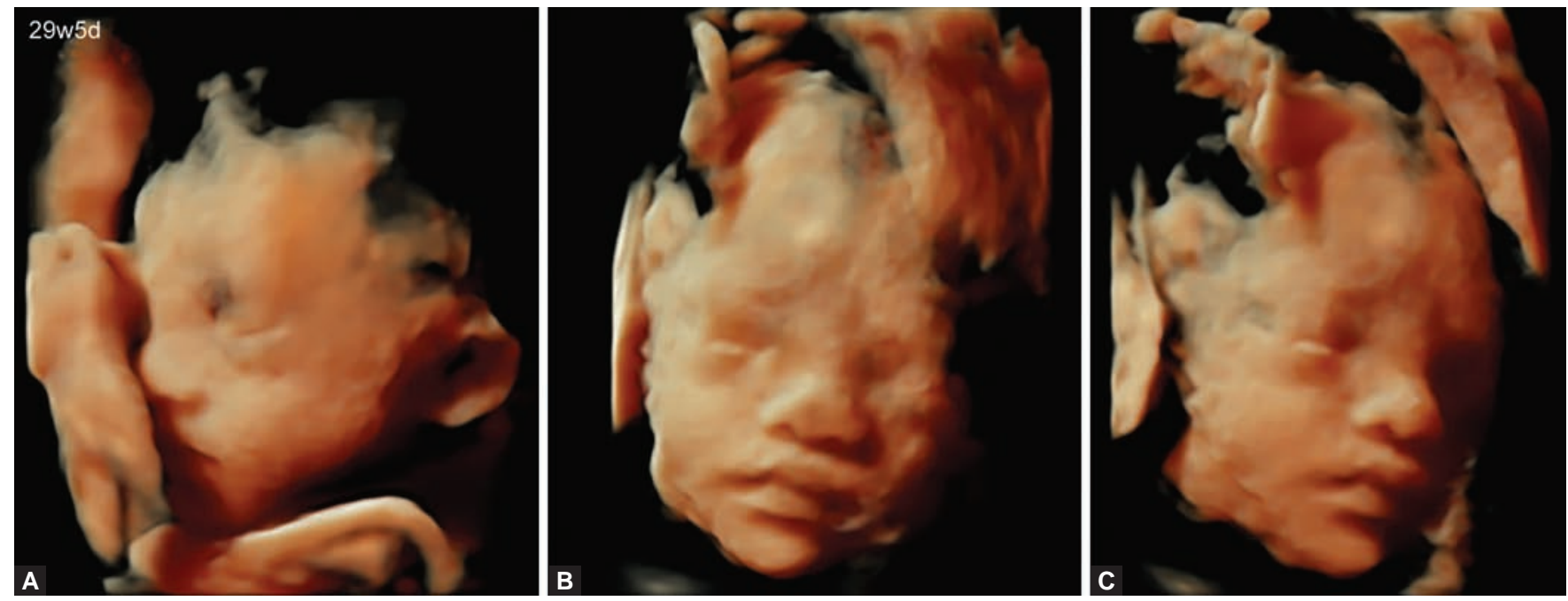

Figs 16A to C: Fetal face reconstructed by HDlive in a case of trisomy 21 at 29 weeks and 5 days of gestation. Low-set ears, a flattened nose, the corners of the mouth turned down, and upward slanting eyes can be recognized: $(A)$ left oblique view, (B) frontal view, and (C) right oblique view (Courtesy: Reprinted with permission from Hanaoka U et al) ${ }^{13}$ 


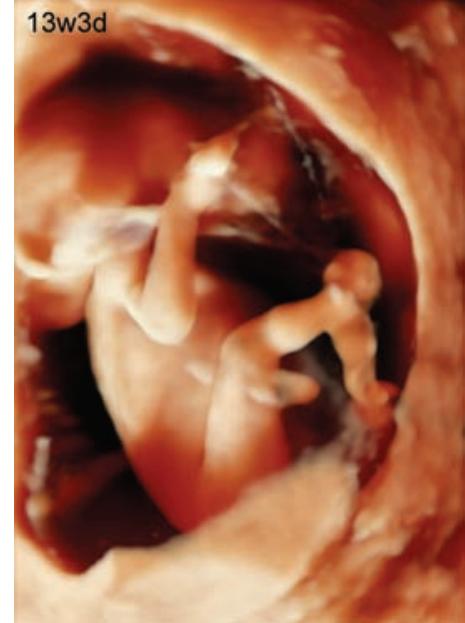

Fig. 17: HDlive image of amniotic band syndrome at 13 weeks and 3 days of gestation. Multiple amniotic bands, a deformed brain, absence of a right finger, and amputation of a right toe are evident

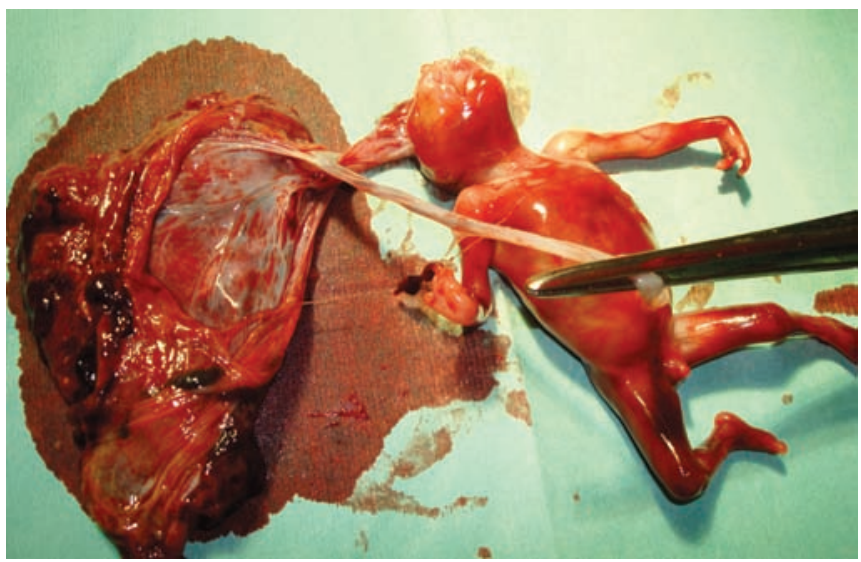

Fig. 19: Photograph of an abortus (Courtesy: Reprinted with permission from Hata T et al $)^{26}$

a proboscis and a dermo-cartilaginous appendix or appendices located above the eye anlage.$^{28}$ HDlive images are more readily discernible than those by
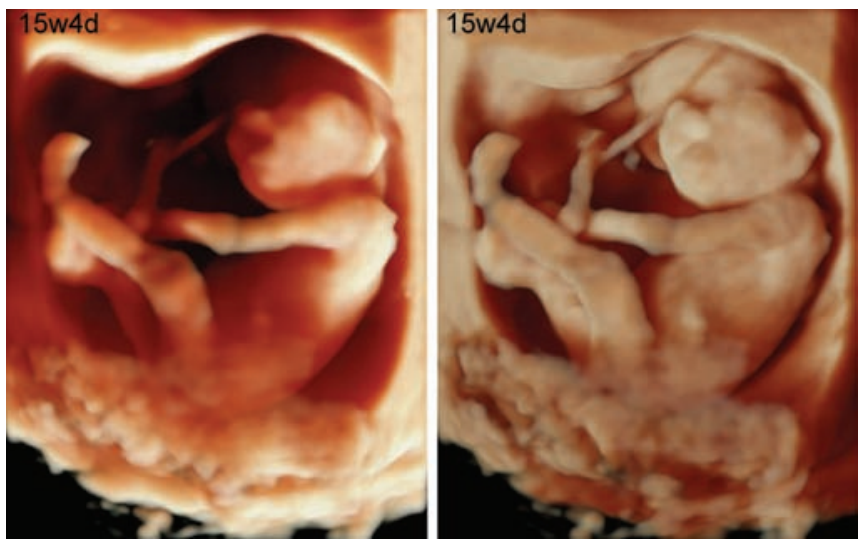

Fig. 18: HDlive images at 15 weeks and 4 days of gestation. A string-like amniotic band, fetal acrania, and cleft lip can be identified. The amniotic band is attached to the fetal brain

conventional 3D sonography, and HDlive shows the same anatomically realistic images with macroscopic findings of cyclopia and a proboscis ${ }^{10}$ (Figs 21 and 22).

\section{Osteogenesis Imperfecta}

Osteogenesis imperfecta includes disorders of the connective tissue and bone fragility, particularly of the skeletal system. ${ }^{29}$ Shortened arms and legs and a deformed head are noted, even in early gestation (Figs 23 and 24). A high forehead is also evident.

\section{Thanatophoric Dysplasia}

A tentative sonographic diagnosis of thanatophoric dysplasia is based on a macrocephalic head, short, angulated, thick arms, legs, hands and feet. ${ }^{29}$ A short thorax and protruding abdomen are also evident. Subtle
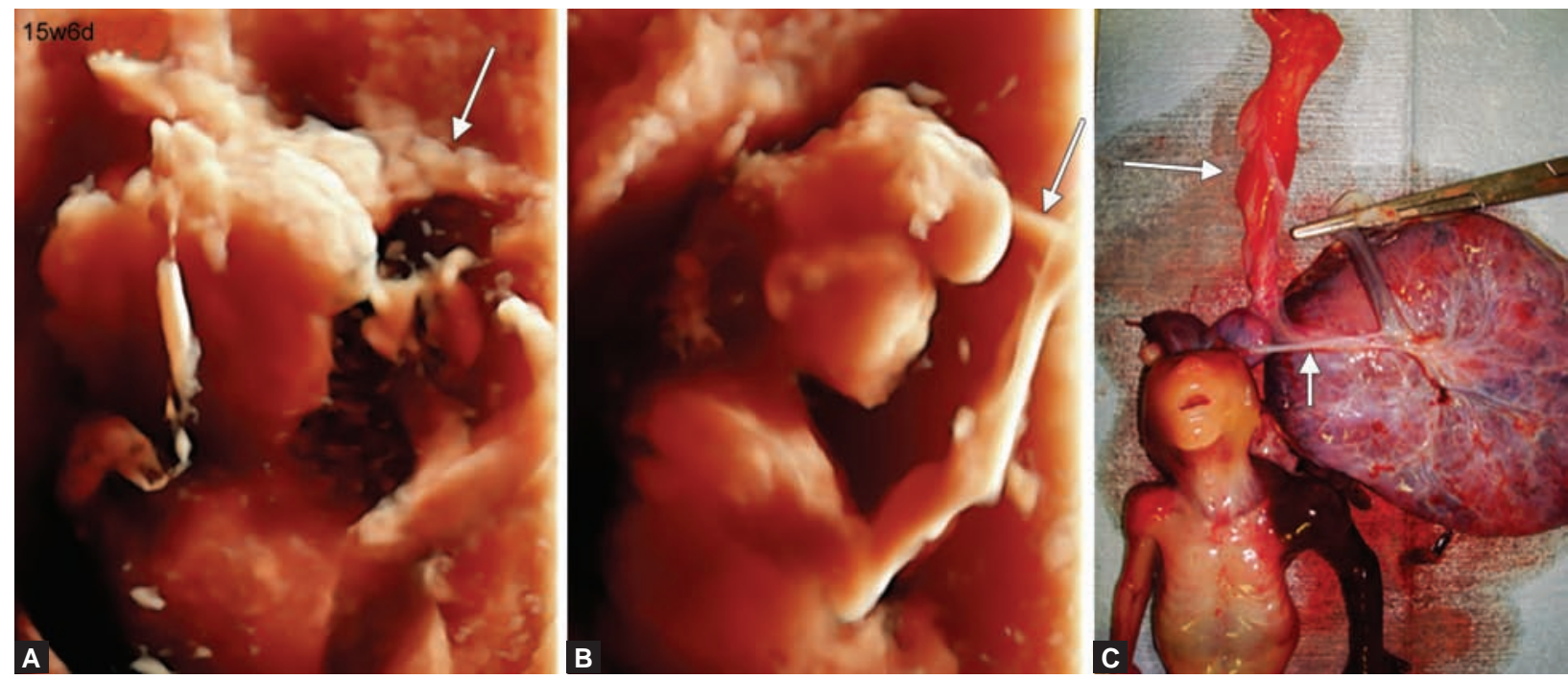

Figs 20A to C: Fetal acrania/exencephaly and two amniotic bands (large and small arrows): (A and B) HDlive images at 15 weeks and 6 days and $(C)$ photograph of the abortus (Courtesy: Reprinted with permission from Hata T et al) ${ }^{27}$ 

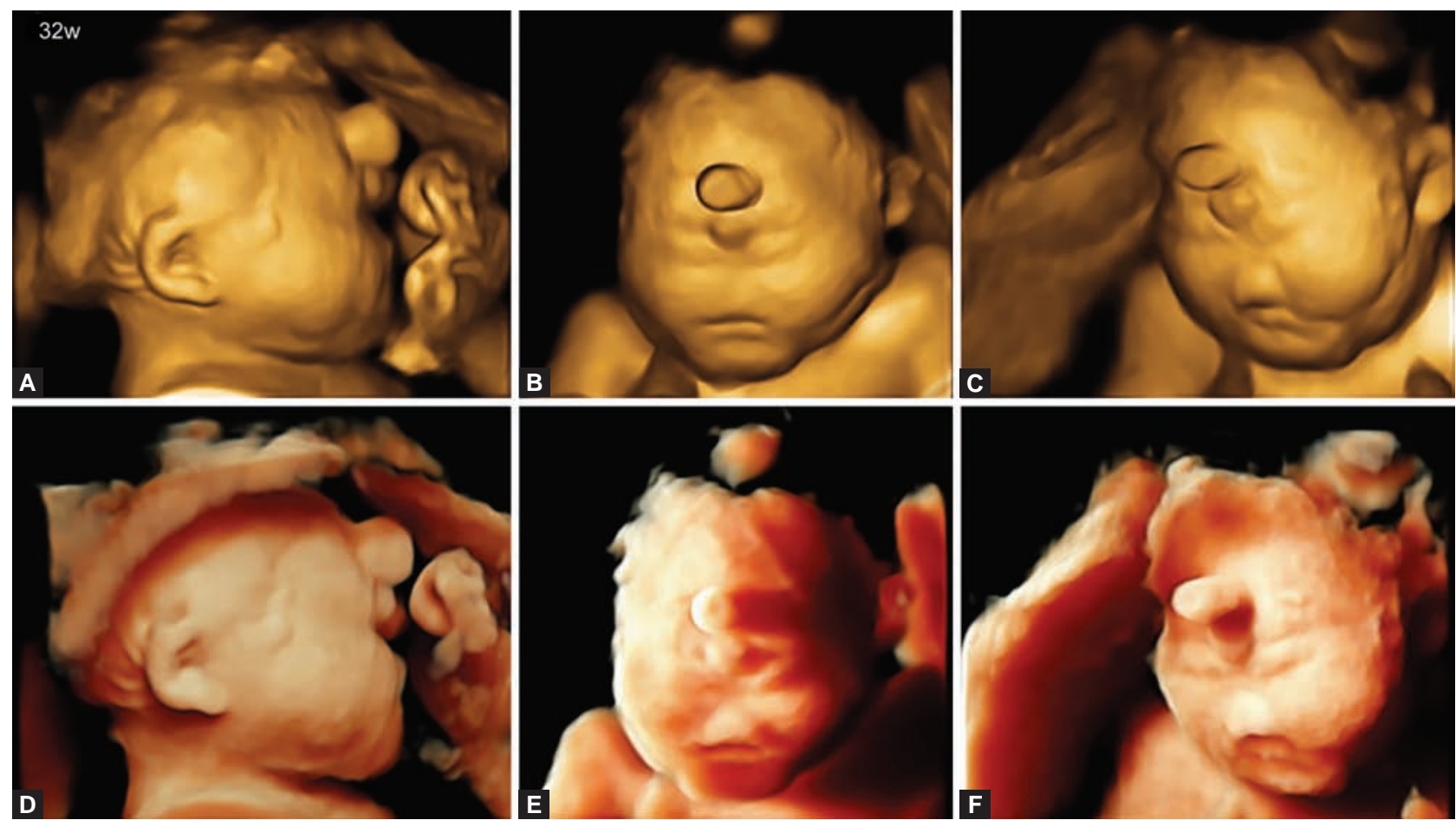

Figs 21A to F: Conventional 3D sonographic ( $A$ to $C$ ) and HDlive (D to F) images of a fetal face with cyclopia and a proboscis at 32 weeks of gestation. HDlive is more effective than conventional 3D ultrasound for the observation of cyclopia and a proboscis: ( $A$ and $D)$ right lateral view, $(B$ and $E)$ frontal view and $(C$ and $F)$ left oblique view (Courtesy: Reprinted with permission from Hata $T$ et al) ${ }^{10}$
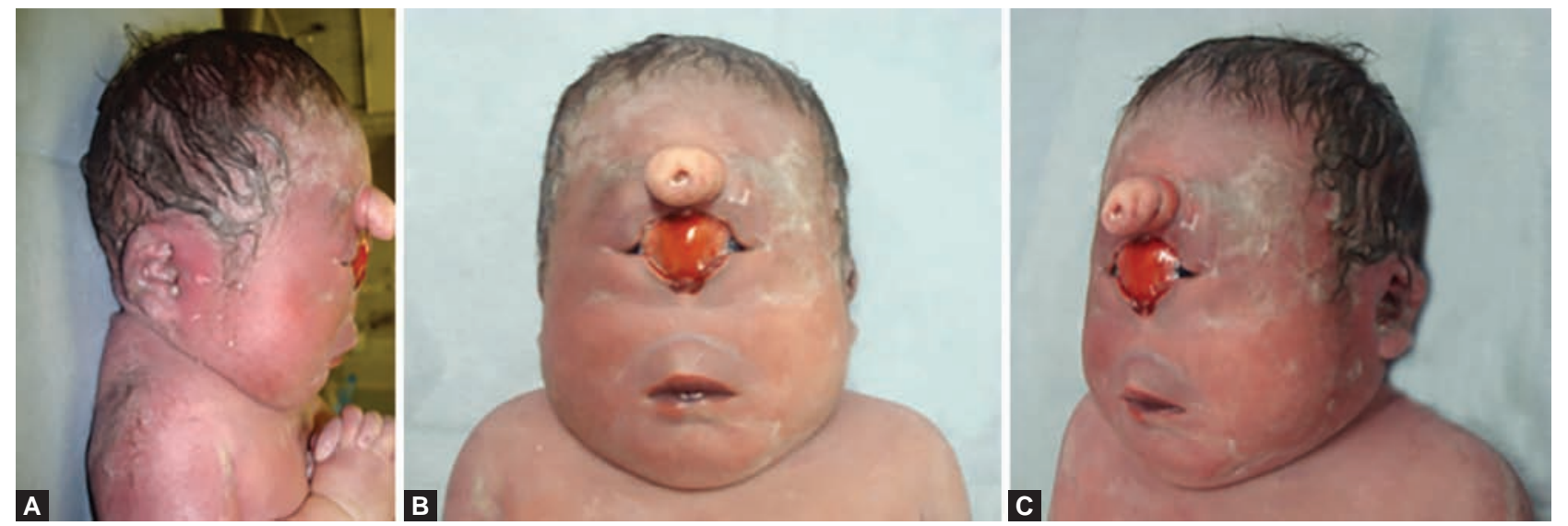

Figs 22A to C: Macroscopic views of the neonatal face. The corresponding right lateral (A), frontal $(B)$ and left oblique (C) facial profiles with prenatal conventional 3D sonographic and HDlive images are clearly depicted (Courtesy: Reprinted with permission from Hata T et al) ${ }^{10}$
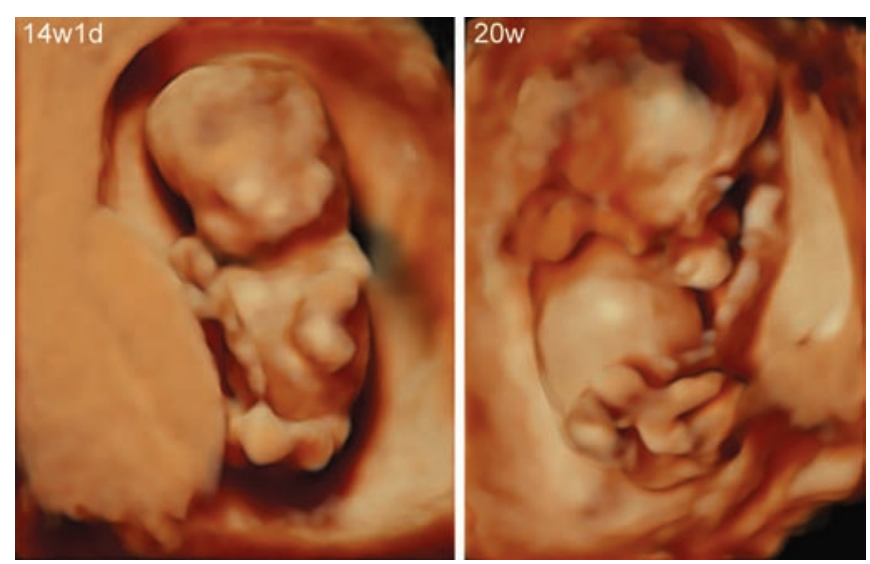

Fig. 23: Osteogenesis imperfecta. Shortened arms and legs and a deformed head are noted at 14 weeks and 1 day and 20 weeks respectively. A high forehead is also evident

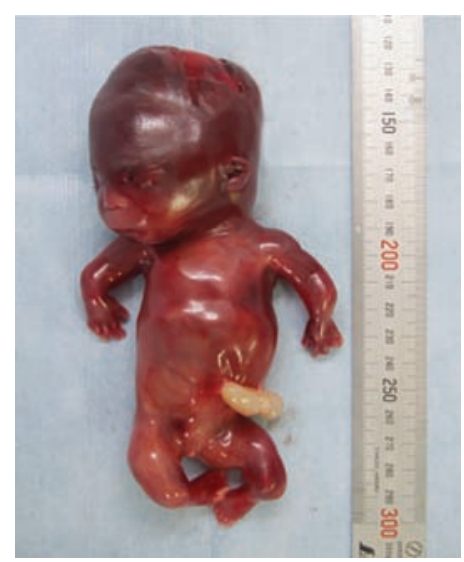

Fig. 24: Photograph of an abortus with osteogenesis imperfecta 

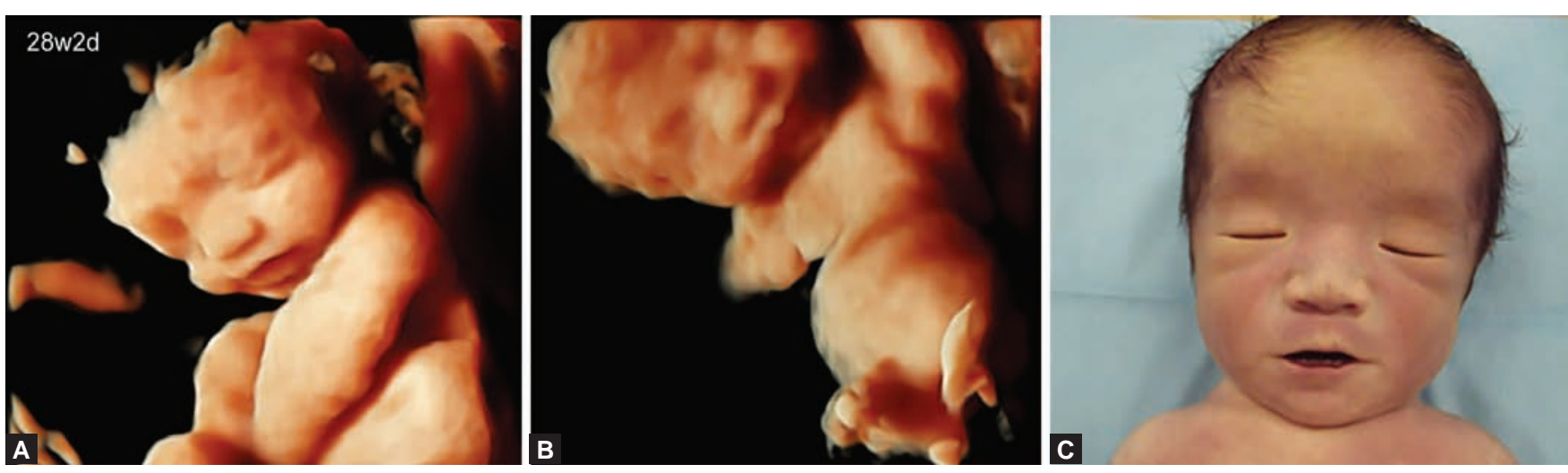

Figs 25A to C: Thanatophoric dysplasia. Subtle facial dysmorphism, involving a flattened nose and broad nasal bridge, is recognized in a case of this skeletal anomaly: (A and B) HDlive images at 28 weeks and 2 days and $(C)$ photograph of the abortus

facial dysmorphism, such as a flattened nose and broad nasal bridge, are recognized in a case of this skeletal anomaly at 28 weeks and 2 days of gestation (Figs $25 \mathrm{~A}$ to C).

\section{Roberts Syndrome}

Roberts syndrome is globally characterized by symmetrical limb reduction of variable severity, craniofacial abnormalities, and pre- and postnatal growth restriction. ${ }^{30,31}$ Bilateral hypoplastic and proximal implantation of the thumb, shortened upper extremities, contracted legs, and the absence of radial and ulnar bones are noted..$^{32}$ Flattening of the face, and exophthalmic eyes can be noted in a case of Roberts syndrome at 20 weeks and 1 day of gestation ${ }^{8}$ (Figs 26A and B).

\section{Micrognathia}

Micrognathia refers to a facial malformation that is characterized by a small chin. 3D surface rendering provides an additional way to qualitatively evaluate the fetal chin from different viewing perspectives. ${ }^{33}$ HDlive clearly shows a realistic fetal profile, so micrognathia could be diagnosed easily (Figs 27A and B).
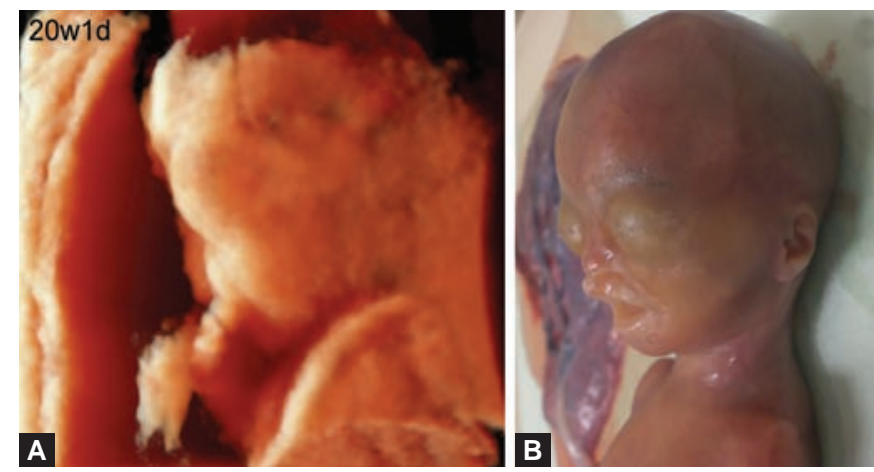

Figs 26A and B: Flattening of the face, and exophthalmic eyes in a case of Roberts syndrome: (A) HDlive image at 20 weeks and 1 day of gestation and (B) photograph of the abortus (Courtesy: Reprinted with permission from Hata T et al) ${ }^{8}$

\section{LIMITATIONS}

'Limitations in optimal visualization of the surface facial structures using HDlive were experienced in cases of an inappropriate fetal position or with faces adjacent to the placenta or uterine wall. These limitations are the same as with conventional 3D ultrasound. Moreover, mastering this technique involves a learning curve, and not all obstetricians and sonographers may be familiar with it..13

\section{CONCLUSION}

HDlive is a new surface-rendering mode, which provides extraordinarily realistic features and near-photographic quality images of the fetal face. ${ }^{8-10}$ HDlive is superior to conventional 3D ultrasound for the depiction of eye fissures because of its shadowing effect. ${ }^{13}$ HDlive may be a useful diagnostic modality for the antenatal evaluation of subtle or minor fetal facial abnormalities, and has the potential to supplement conventional 2D/3D sonography in diagnosing fetal facial abnormalities. For the future application of this technique, its other advantages in the antenatal diagnosis of fetal facial anomalies must be investigated.
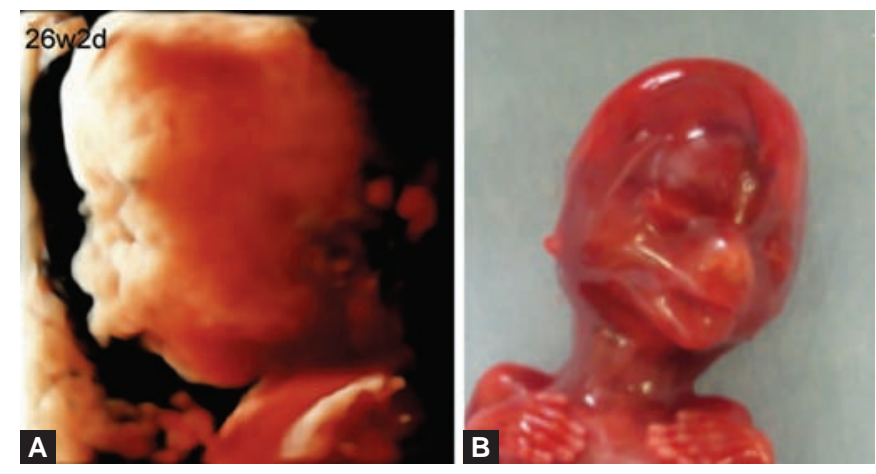

Figs 27A and B: Micrognathia: (A) HDlive clearly shows micrognathia and skin edema at 26 weeks and 2 days and (B) photograph of the abortus 


\section{ACKNOWLEDGMENTS}

The work reported in this paper was supported by a Grant-in-Aid for Scientific Research on Innovative Areas 'Constructive Developmental Science' (No. 24119004), and a Research Grant (No. 25462561) from The Ministry of Education, Culture, Sports, Science and Technology, Japan.

\section{REFERENCES}

1. Hata T, Yonehara T, Aoki S, Manabe A, Miyazaki K. Threedimensional sonographic visualization of the fetal face. Am J Roentgenol 1998;170(2):481-483.

2. Manabe A, Hata T, Aoki S, Matsumoto M, Yanagihara T, Yamada Y, Irikoma S, Miyazaki K. Three-dimensional sonographic visualization of fetal facial anomaly. Acta Obstet Gynecol Scand 1999;78(10):917-918.

3. Tanaka Y, Miyazaki T, Kanenishi K, Tanaka H, Yanagihara T, Hata T. Antenatal three-dimensional sonographic features of Treacher Collins syndrome. Ultrasound Obstet Gynecol 2002;19(4):414-415.

4. Rustico MA, Lalatta F, Righini A, Spaccini L, Fabietti I, Nicolini U. The role of integrated imaging techniques for prenatal prediction of phenotype in two cases of facial anomalies. Prenat Diagn 2004;24(7):508-512.

5. Hanprasertpong T, Hanaoka U, Zhang X, Mori N, Inubashiri E, Kanenishi K, Yamashiro C, Tanaka H, Shiota A, Yanagihara T, Hata T. Three-dimensional sonographic features of a fetus with Wolf-Hirschhorn syndrome. J Med Ultrasonics 2008;35(4):197-199.

6. Anderson C, Matias A, Merz E. Fetal face: The whole picture. Ultraschall in Med 2012;33(5):431-440.

7. Akiyama M, Okubo T, Yasuo T, Iwasaku K, Kitawaki J. Prenatal diagnosis of agnasthia-otocephaly using sonography and magnetic resonance imaging. J Ultrasound Med 2013;32(8):1522-1526.

8. Hata T, Hanaoka U, Tenkumo C, Sato M, Tanaka H, Ishimura M. Three- and four-dimensional HDlive rendering images of normal and abnormal fetuses: pictorial essay. Arch Gynecol Obstet 2012;286(6):1431-1435.

9. Hata T, Hanaoka U, Mashima M, Ishimua M, Marumo G, Kanenishi K. Four-dimensional HDlive rendering image of fetal facial expression: a pictorial essay. J Med Ultrasonics 2013;40(4):437-441.

10. Hata T, Hanaoka U, Mashima M. HDlive rendering image of cyclopia and a proboscis in a fetus with normal chromosomes at 32 weeks of gestation. J Med Ultrasonics 2014;41(1):109-110.

11. Kagan KO, Pintoffl K, Hoopmann M. First-trimester ultrasound images using HDlive. Ultrasound Obstet Gynecol 2011;38(5):607.

12. Merz E. Surface reconstruction of a fetus $(28+2 \mathrm{GW})$ using HDlive technology. Ultraschall in Med 2012;33(3):211-212.

13. Hanaoka U, Tanaka H, Koyano K, Uematsu R, Kanenishi K, Hata T. HDlive imaging of the face of fetuses with autosomal trisomies. J Med Ultrasonics 2014;41(3):339-342.

14. Hata T, Kanenishi K, Hanaoka U, Uematsu R, Marumo G, Tanaka H. HDlive study of fetal development and behavior. Donald School J Ultrasound Obstet Gynecol 2014;8(3):250-265.

15. Reissland N, Francis B, Mason J, Lincoln K. Do facial expressions develop before birth? PLoS ONE 2011;6(8):e24081. doi:10.1371/journal.pone.0024081.

16. Papp C, Beke A, Ban Z, Szigeti Z, Toth-Pal E, Papp Z. Prenatal diagnosis of trisomy 13. Analysis of 28 cases. J Ultrasound Med 2006;25(4):429-435.
17. Szigeti Z, Csapo Z, Joo JG, Pete B, Papp Z, Papp C. Correlation of prenatal ultrasound diagnosis and pathologic findings in fetuses with trisomy 13. Prenat Diagn 2006;26(13):1262-1266.

18. MedlinePlus. Trisomy 13. Available at: http://www.nlm.nih. gov/medlineplus/ency/artcle/001660.htm [3 October 2013].

19. Pitukkijronnakorn S, Promsonthi P, Panburana P, Rangsiprakarn R, Chittacharoen A. Prenatal ultrasonographic findings in 'trisomy 13'. J Med Assoc Thai 2008;91(11):1651-1655.

20. Yeo L, Guzman ER, Day-Salvatore D, Walters C, Chavez D, Vinyzileos AM. Prenatal detection of fetal trisomy 18 through abnormal sonographic features. J Ultrasound Med 2003;22(6): 581-590.

21. Szigeti Z, Csapo Z, Joo J, Pete B, Papp Z, Papp C. Quality control of prenatal sonography in detecting trisomy 18 . The value of perinatal autopsy. Early Hum Dev 2007;83(8):505-509.

22. Wikipedia. Edwards syndrome. Available at: http:// en.wikipedia.org/wiki/Edwards_syndrome [3 October 2013].

23. Szigeti Z, Csaba Á, Pete B, Hajdu J, Papp Z, Papp C. Correlation of prenatal sonographic diagnosis and morphologic findings of fetal autopsy in fetuses with trisomy 21. J Ultrasound Med 2007;26(1):61-68.

24. US National Library of Medicine. Down syndrome. Available at: http://www.ncbi.nlm.gov/pubmedhealth/PMH0001992/ [3 October 2013].

25. Inubashiri E, Hanaoka U, Kanenishi K, Yamashiro C, Tanaka H, Yanagihara T, Hata T. 3D and 4D sonographic imaging of amniotic band syndrome in early pregnancy. J Clin Ultrasound 2008;36(9):573-575.

26. Hata T, Tanaka H, Noguchi J. 3D/4D sonographic evaluation of amniotic band syndrome in early pregnancy: a supplement to 2D ultrasound. J Obstet Gynecol Res 2011;37(6):656-660.

27. Hata T, Uketa E, Tenkumo C, Hanaoka U, Kanenishi K, Tanaka H. Three- and four-dimensional HDlive rendering image of fetal acrania/exencephaly in early pregnancy. J Med Ultrasonics 2013;40(3):271-273.

28. Bonilla-Musoles F, Machado LE, Raga F, Castillo JC, OsborneN, Bonilla F Jr, Machado F. 3D/4D US in fetal malformations. Part 2. Second trimester: Cephalic pole malformations; in Hata T, Kurjak A, Kozuma S, editors. Current Topics on Fetal 3D/4D Ultrasound, Bentham Science Publishers 2011;56-86. Available at: www.bentham.org/ebooks/9781608050192/index.htm

29. Bonilla-Musoles F, Machado LE, Raga F, Castillo JC, Osborne N, Bonilla F Jr, Machado F. 3D/4D US in fetal malformations. Part 3. Second trimester: Skeletal disorders, thoracic, abdominal, kidney and other malformations; in Hata T, Kurjak A, Kozuma S, editors. Current Topics on Fetal 3D/4D Ultrasound, Bentham Science Publishers 2011;87-113. Available at: www.bentham.org/ebooks/9781608050192/index.htm

30. Stioui S, Priviteria O, Brambati B, Zuliani G, Lalatta F, Simoni, G. First-trimester prenatal diagnosis of Roberts Syndrome. Prenat Diagn 1992;12(2):145-149.

31. Otano L, Matayoshi T, Gadow E. Roberts syndrome: firsttrimester prenatal diagnosis. Prenat Diagn 1996;16(8):770-771.

32. Dulnuan DJ, Matsuoka M, Uketa E, Hayashi K, MurotsukiJ, Nishimura G, Hata T. Antenatal three-dimensional sonographic features of Roberts syndrome. Arch Gynecol Obstet 2011;284(1):241-244.

33. Lee W, McNie B, Chaiworapongsa T, Conoscenti G, KalacheKD, Vettraino IM, Romero R, Comstock CH. Three-dimensional ultrasonographic presentation of micrognathia. J Ultrasound Med 2002;21(7):775-781. 